\title{
Measurement of Energy Expenditure while Playing Exergames at a Self- selected Intensity
}

\author{
Bryan L. Haddock*, Sarah Jarvis, Nicholas R. Klug, Tarah Gonzalez, Bryan Barsaga, \\ Shannon R. Siegel and Linda D. Wilkin
}

California State University, San Bernardino, CA 92407, USA

\begin{abstract}
Exergames have been suggested as a possible alternative to traditional exercise in the general population. The purpose of this study was to examine the heart rate (HR) and energy expenditure (EE) of young adults playing several different exergames, while self-selecting the component of the game to play and the intensity. A total of 117 participants, 18-35 years of age, were evaluated on one of four active video games. Participants were free to choose any component of the given game to play and they played at a self-selected intensity. The average HR and EE during the individual games were compared to resting conditions and to the American College of Sports Medicine (ACSM) guidelines. The HR and EE increased above resting conditions during each game $(\mathrm{p}<0.05)$. When the results of all games were combined, the HR was $125.4 \pm 20.0 \mathrm{bpm}$ and the average EE was $6.7 \pm 2.1 \mathrm{kcal} / \mathrm{min}$. This HR represents an average percent of heart rate reserve of $44.6 \pm 14.1$, high enough to be considered moderate intensity exercise. If performed for 30 minutes a day, five days per week, the average EE would be 1,005 kcals, enough to meet the ACSM recommendations for weekly EE. Therefore, at least some exergames could be a component of an exercise program.
\end{abstract}

Keywords: Exercise, exergaming, game play, heart rate, moderate exercise, video games.

\section{INTRODUCTION}

Physical inactivity in the United States continues to be a significant public health concern due to its relation to a number of chronic diseases [1]. According to the Centers for Disease Control and Prevention (CDC), Healthy People 2010 Database, $36 \%$ of adults 18 years and older reported no leisure-time physical activity [2]. The reason for the high level of sedentary lifestyles is multifaceted. Methods of transportation and communication, along with advanced workplace and entertainment technologies have all evolved to promote sedentary behaviors. A Kaiser Family and Foundation study noted that in 2009 the average amount of time spent on sedentary media activities such as television watching and the playing of video/computer games was 10 hours and 45 minutes in a typical day for young adults [3].

The American College of Sports Medicine (ACSM), American Heart Association (AHA), and the United States Surgeon General all recommend accumulating enough physical activity per week to expend at least 1,000 kilocalories (kcals) [1]. It has been estimated that this level of physical activity can be attained with approximately 150 minutes per week, or 30 minutes per day, five days per week of physical activity $[4,5]$. Exercise intensity is often defined in terms of moderate or vigorous. Moderate intensity exercise is defined as 40 to $<60 \%$ of Heart Rate Reserve (HRR) whereas anything above $60 \%$ of HRR would be considered vigorous. Larger dosages of physical activity are likely to lead to increased benefits. However, 1,000 kcal per

*Address correspondence to this author at the California State University, San Bernardino, CA 92407, USA; Tel: (909)537-5359; Fax: (909)537-7085; E-mail: bhaddock@csusb.edu week is typically recommended as the minimum level in order to achieve health benefits. The Surgeon General states that adhering to such recommendations can be an effective preventative strategy against cardiovascular disease, obesity, stroke, depression, hypertension, diabetes, and certain cancers $[1,4]$.

Researchers have been investigating effective ways to increase physical activity in the general population. Interactive video games, often called exergames, have been postulated as a potential mechanism for increasing physical activity in those who otherwise would be unlikely to meet physical activity recommendations. Many studies have examined the level of energy expenditure (EE) while individuals participated in exergaming. Several studies report that the heart rate (HR) and EE noted during the playing of these exergames indicated light to moderate intensity exercise and often did not meet the minimal requirements to contribute to overall health through exercise [6-8].

In several studies using exergames, the EE or HR did reach the minimum cut-off points for health and fitness according to ACSM standards. Many studies have been conducted with children [9-14]. A few studies with adults have also shown an intensity high enough to meet the ACSM standards [8,15-19]. One of the first studies investigating the exercise intensity of exergames examined DanceDance Revolution ${ }^{\circledR}$ (DDR) in which participants had an average heart rate of $137 \mathrm{bpm}$, falling within the range of moderate intensity exercise [18].

Most studies to date have examined EE in strictly defined settings that are not necessarily what would be found if 
participants were playing on their own. It is often difficult to compare results of different studies due to varied procedures that are used to evaluate most exergames. For instance, in one of the first studies examining DDR $\AA$, the playing time was limited to approximately 10.4 minutes [18]. A study examining the Nintendo Wii Sports had the participants play each videogame for 15 minutes [20]. In a study examining the Sony Eye Toy Knockout (boxing), Home Run (baseball), Groove (dancing upper body), Anti-grav (hover-board) and PlayStation 2 Dance UK (dance pad) game play was limited to 5-8 minutes on each specific game [12]. Established time periods that participants play each part of a particular game and fixed rest periods between game components are beneficial for consistent data, however this limits the ability to generalize in circumstances when individuals play the game on their own. In most of the studies to date, participants were unable to self-select variables within the game and/or the level (intensity) of play. For instance, if an individual played Wii Sports at home, they might spend most of their time on one of the sports and little or no time on another. When participants are unable to choose their own game and level of intensity, they may be less likely to be motivated, and in return not work as hard at that game. In order to truly determine if exergames could be used as a component of an exercise program, these games need to be studied under real-life settings, where individuals are allowed to choose the component of the game, and the intensity level, therefore playing at a selfselected pace.

Very few studies have examined exergames while allowing participants to self-select the component of the game to play and the level (intensity) at which to play [10]. Thus, the purpose of this study was to examine the HR and EE of participants playing exergames, utilizing a procedure that would as much as possible in a laboratory setting, mimic an individual playing the same game at home.

\section{METHODS}

A total of four different games were evaluated, the first three were part of the Nintendo Wii ${ }^{\circledR}$ console: "Gold's Gym: Cardio Workout", "Your Shape", and "Just Dance", and the fourth game was on the XBOX 360 Kinect console: "The Biggest Loser: Ultimate Workout."

\section{Subjects}

All participants were recruited from a university student population. All participants were between 18-35 years of age and free of known cardiac or metabolic disease. A total of 117 individuals participated in this study. Participant recruitment was independently conducted for each game studied. Twenty seven students (15 males, 12 females) were tested for Gold's Gym: Cardio Workout, 31 students (17 males, 14 females) were tested for "Your Shape", 25 students (9 males, 16 females) were tested for "Just Dance", and 34 students (21 males, 13 females) were tested for "The Biggest Loser: Ultimate Workout". Each participant's height and weight were evaluated on a stadiometer (Detecto; Missouri, USA) and a standard balance scale, to the nearest 0.1 centimeters $(\mathrm{cm})$ and 0.1 kilograms $(\mathrm{kg})$, respectively. Body Mass Index was calculated for each participant as weight in kilograms divided by height in meters squared $\left(\mathrm{kg} / \mathrm{m}^{2}\right)$. The research protocol was approved by the University Institutional Review Board (IRB).

\section{Procedures}

Each participant was scheduled for two appointments: (1) a familiarization session, and (2) a metabolic testing session while playing one of the exergames. At the initial session, each participant read and signed an informed consent. Following this, a health history form was completed to make sure there were no contraindications to testing. Upon clearance, each participant was familiarized with the testing equipment, and the game on which he/she would be evaluated.

At the familiarization session, each participant was shown the portable metabolic cart (Viasys Oxycon mobile Yorba Linda, CA) including the mask and HR monitor (Polar, Inc., USA) that they would wear during the testing session. They were then given a demonstration of the exergame they would play, including how to maneuver between the various components of the game. Each participant was then allowed to play the game that would be utilized in the study. Participants were allowed to play the game during this session for as long as they wanted until they reported that they understood the game, including how to play the game and how to switch between components of the game. No time limit was given, as some individuals were quite comfortable with gaming, while others did not have as much experience. After the familiarization session, the participants were scheduled for their testing session, which was conducted on a different date. They were instructed to avoid food for at least four hours prior to testing, although water was allowed. They were also asked to not participate in any moderate to vigorous intensity physical activities for at least four hours prior to their testing time. Participants were told to wear comfortable clothing and shoes for exercise when coming to the testing session. All participants were reminded the day before their scheduled test date via text message or phone call.

On testing day, each participant reported to the lab. After the measurement of height and weight, the participants were connected to the portable metabolic cart and HR monitor. Prior to each test, the $\mathrm{O}_{2}$ and $\mathrm{CO}_{2}$ sensors were calibrated with a known gas concentration, along with a volume calibration.

Once the mask was sealed properly on the participant's face, and the participant stated that he/she was comfortable with the mask and HR monitor, the participant was lead to the resting area to sit in a comfortable chair inside a room with the door slightly ajar to allow a small amount of light. The subject was told to relax for the next 10 minutes while expired gases were being captured breath-by-breath and the $\mathrm{HR}$ was recorded. Baseline oxygen consumption $\left(\mathrm{VO}_{2}\right)$ and carbon dioxide production $\left(\mathrm{VCO}_{2}\right)$ were measured in order to determine a baseline level of EE. In addition, HR was monitored to determine a baseline HR. The last five minutes of this time was used as the recorded baseline for HR and EE. After the 10-minute baseline recording session, while remaining connected to the metabolic cart and the HR monitor, the participant walked across the lab to where the game was to be played. When the participant was ready, they 
could begin playing. The time started when the first game playing movement was made. The total time for each game was determined as the time from the first game movement until the designated elapsed time for the game. In order to try and simulate what would occur when individuals would play the game on their own the participants were given free choice to play any of the components within the particular game, at any desired level or intensity. The decision on which component of the game to play was made as they played. Following completion of the game, participants were disconnected from the metabolic cart and HR monitor. Each participant was then asked to rate his/her level of exertion based on Borg's Rating of Perceived Exertion Chart [21]. This is commonly used in exercise studies to assess the intensity at which a person feels they are working. We used the 6-20 scale in which the numbers align with statements such as "no exertion at all for a rating of 6, to "somewhat hard" for a rating of 13, to "maximal exertion" for a rating of 20.

These instructions were followed for each of the games tested. The goal of these tests was to determine the average HR and EE for each of the games while giving participants the freedom to play as they would if playing on their own, within the specified time frame. The specifics regarding the protocol for each game are listed below.

\section{Your Shape}

The game has two components (strength and cardiorespiratory) and was therefore treated as two separate games lasting 15 minutes each, for a total of 30 minutes. This time frame was chosen because it fits within the pre-programmed options within the game. Each participant was shown a pair of dumbbells that were to be utilized during the strength section of the workout; 10 pounds for males and 5 pounds for females. They were also shown the mat they would use during floor exercises and cool down. A UBI Soft ${ }^{\circledR}$ camera was used to monitor the position and accuracy of the movements.

\section{Gold's Gym: Cardio Workout}

The researcher set up the game by choosing "A La Carte" mode and then the Shape Boxing option. Data were gathered through the Shape Boxing option during actual testing. The participants were instructed to choose the Basic level for an introduction of the type of punches and movements required and then they were free to choose between Beginner, Intermediate, or Advanced levels. In order to keep the time frame within the amount recommended by the ACSM standards [4] for an aerobic exercise session participant played for a 20-minute session.

\section{Just Dance}

During the familiarization session, each participant chose seven songs that they wanted to dance to during the testing session. During the testing session, the participants moved from one song to the next once they finished dancing to a particular song. If they desired, they were allowed to repeat a song instead of moving on to one of their other chosen songs. Each participant was monitored for his/her 20-minute session.

\section{The Biggest Loser: Ultimate Workout}

The game was calibrated for each participant by positioning him/her in an area assigned by the game. This position was matched by a small figure on the screen. This allowed the Kinect ${ }^{\circledR}$ camera to align itself based on the person's reflected silhouette on the screen. The participants were allowed to play any portion of the game they desired. All movements were detected using the Kinect ${ }^{\circledR}$ camera. Each participant played for a 20-minute session.

\section{Data Analyses}

All data were analyzed using SPSS 16.0. Descriptive data (Mean \pm SD) were calculated for the age in years, height in centimeters, weight in kilograms, BMI $\left(\mathrm{kg} / \mathrm{m}^{2}\right)$, EE (kcals/min. and total kcals) and HR (beats per minute - bpm) at baseline and during the exercise time. Each game was compared to the ACSM guidelines for target HR and EE. Since the "Your Shape" game has both a cardio and strength component, each component was treated as its own game and then the data from the two components were combined for an average value. The data from each of the four games was pooled to get an average value across the games. A Multivariate Analysis of Variance (MANOVA) was utilized to compare the games with each other to determine if any significant differences occurred between the games. A probability value of less than 0.05 was considered statistically significant, and a Bonferroni adjustment was used to correct for multiple comparisons. Paired sample $t$ tests were used to compare mean values during activity to baseline for each of the individual games.

\section{RESULTS}

Descriptive data of the participants are provided in Table 1. There was a separate group of participants for each of the four games. There were no significant differences between the participants for any of the descriptive characteristics ( $p>0.05)$.

Table 1. Descriptive Data (Mean \pm SD)

\begin{tabular}{|l|l|l|l|l|}
\hline Game & Age (Years) & Height $(\mathbf{c m})$ & Weight $(\mathbf{k g})$ & BMI $\left(\mathbf{k g} / \mathbf{m}^{2}\right)$ \\
\hline \hline Gold's Gym (n=27) & $22.6 \pm 2.0$ & $170.8 \pm 9.4$ & $71.9 \pm 15.5$ & $24.4 \pm 4.0$ \\
\hline Biggest Loser (n=34) & $23.4 \pm 2.5$ & $171.4 \pm 10.6$ & $74.2 \pm 21.6$ & $26.0 \pm 4.8$ \\
\hline Just Dance (n=25) & $22.1 \pm 2.6$ & $164.2 \pm 9.4$ & $65.7 \pm 12.2$ & $24.3 \pm 3.1$ \\
\hline Your Shape (n=31) & $22.6 \pm 2.1$ & $168.9 \pm 10.0$ & $69.9 \pm 17.8$ & $24.2 \pm 4.0$ \\
\hline Pooled Data (n=117) & $22.7 \pm 2.3$ & $169.1 \pm 10.2$ & $70.7 \pm 17.6$ & $24.8 \pm 4.1$ \\
\hline
\end{tabular}


EE and HR results are presented in Table 2. Baseline HR, while the participants were at rest prior to testing did not significantly differ between the games. The EE at baseline was significantly greater for the participants of the Gold's Gym game than it was for the participants of the Just Dance game $(p<0.01)$. Calculating EE over a week's time $(150$ minutes per week of activity utilizing a similar game or other activity) would meet the ACSM Guidelines for weekly EE in all games except for the Just Dance game (Fig. 1).

According to the MANOVA, the average EE and HR increased above baseline conditions while participants played each of the games $(p<0.05)$. The post hoc analyses showed that gross EE was significantly lower in the "Just Dance" game than in either "Gold's Gym" or the cardio component of the "Your Shape" game $(p<0.05)$, if controlling for body weight the significance is lost $(p>0.05)$. The average HR during game play was significantly lower in the "Just Dance" game than in the cardio portion of "Your Shape" $(p<0.05)$ (Table 2). When all of the games were pooled, the average HR while playing the exergames was $125 \pm 20 \mathrm{bpm}$, while the average EE was $6.7 \pm 2.1 \mathrm{kcal} / \mathrm{min}$ (Table 2). The pooled mean RPE was 11.0 (corresponding to a statement of "light"). The RPE was not significantly different between the various games $(\mathrm{p}>0.05)$.

Table 2. EE and HR at Baseline and During Game Play (Mean \pm SD)

\begin{tabular}{|c|c|c|c|c|c|c|}
\hline GAME & $\begin{array}{l}\text { Baseline EE } \\
\text { (kcal/min) }\end{array}$ & $\begin{array}{l}\text { Gross EE } \\
\text { (kcal/min) }\end{array}$ & $\begin{array}{l}\text { Gross EE } \\
\text { (kcal/hr. per kg) }\end{array}$ & $\begin{array}{l}\text { Resting HR } \\
\text { (bpm) }\end{array}$ & $\begin{array}{l}\text { Average HR } \\
\text { (bpm) }\end{array}$ & $\begin{array}{l}\text { Average Percent } \\
\text { HRR }(\%)\end{array}$ \\
\hline Gold's Gym & $1.5 \pm 0.30^{*}$ & $7.2 \pm 2.3^{\dagger}$ & $6.0 \pm 1.9$ & $70 \pm 18$ & $126 \pm 23^{\dagger}$ & $44.1 \pm 15.9$ \\
\hline Biggest Loser & $1.3 \pm 0.35$ & $7.0 \pm 1.9^{\dagger}$ & $5.6 \pm 1.6$ & $66 \pm 11$ & $126 \pm 20^{\dagger}$ & $47.3 \pm 12.7$ \\
\hline Just Dance & $1.1 \pm 0.21$ & $5.3 \pm 1.9^{\dagger \neq}$ & $4.8 \pm 1.7$ & $71 \pm 12$ & $117 \pm 19^{\dagger}$ & $36.0 \pm 14.3$ \\
\hline Your Shape (Cardio) & $1.3 \pm 0.28$ & $7.9 \pm 2.3^{\dagger}$ & $6.8 \pm 2.0$ & $68 \pm 11$ & $134 \pm 17^{\dagger^{*}}$ & $49.2 \pm 10.8$ \\
\hline Your Shape (Strength) & $1.3 \pm 0.28$ & $6.1 \pm 1.5^{\dagger}$ & $5.2 \pm 1.3$ & $68 \pm 11$ & $128 \pm 17^{\dagger}$ & $51.1 \pm 11.1$ \\
\hline $\begin{array}{l}\text { Your Shape } \\
\text { (Combined data) }\end{array}$ & $1.3 \pm 0.28$ & $7.0 \pm 1.9^{\dagger}$ & $6.0 \pm 1.6$ & $68 \pm 11$ & $131 \pm 17^{\dagger}$ & $46.7 \pm 10.9$ \\
\hline Pooled Data & $1.3 \pm 0.31$ & $6.7 \pm 2.1^{\dagger}$ & $5.7 \pm 1.8$ & $69 \pm 13$ & $125 \pm 20^{\dagger}$ & $44.6 \pm 14.1$ \\
\hline
\end{tabular}

Note: Resting data for Your Shape is the same for Cardio, Strength and Combined data because it was the same participants, the only difference is in values during playing the various components (strength, cardio, or combined). Pooled data is an average of each of the games: Gold's Gym, Biggest Loser, Just Dance, and Your Shape (combined data only for this game)

* Significantly different from Just Dance $(\mathrm{p}<0.05)$

${ }^{\dagger}$ Significantly different from baseline values $(\mathrm{P}<0.01)$

* Significantly different from Gold’s Gym and Your Shape Cardio portion

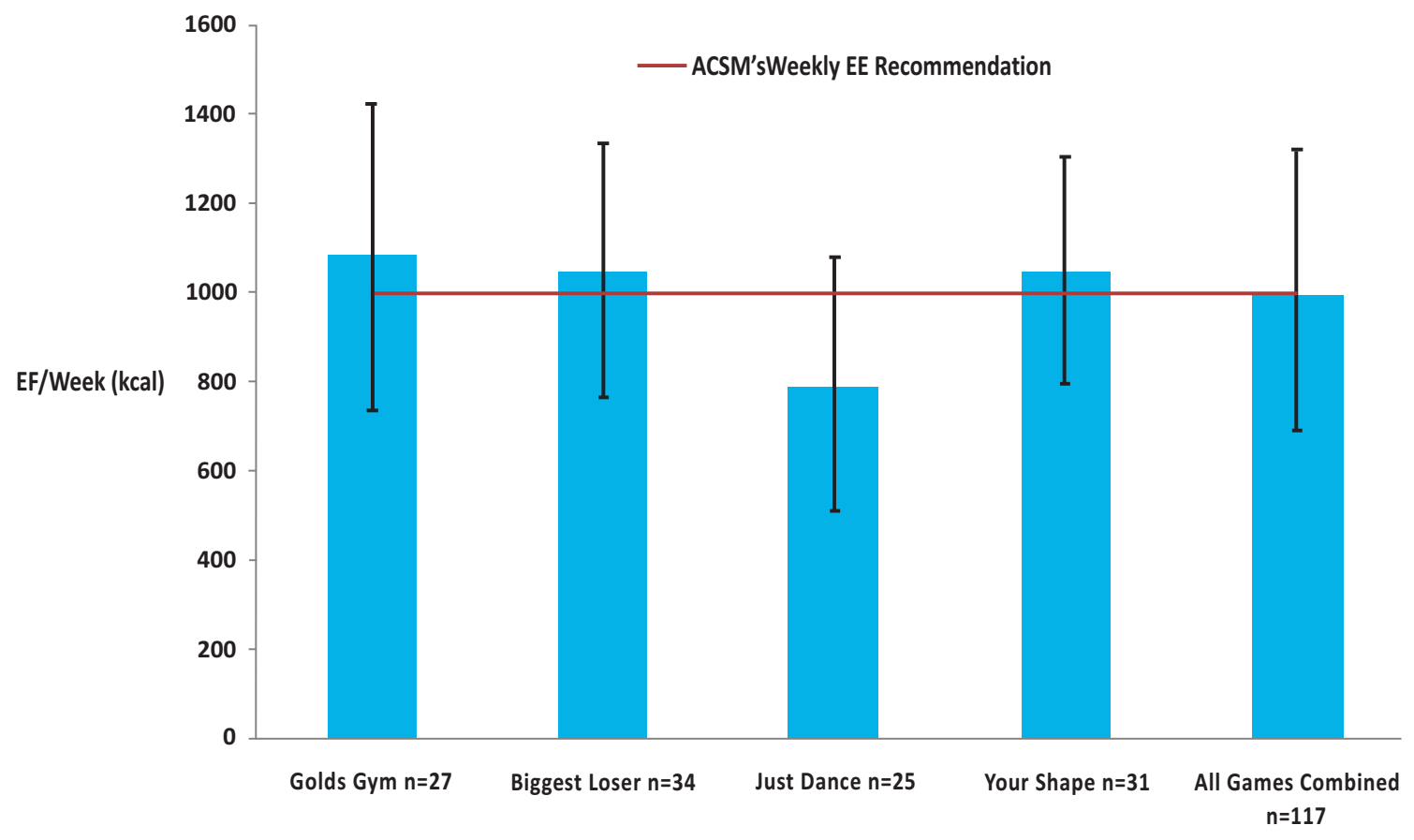

Game

Fig. (1). Estimated weekly energy expenditure. 


\section{DISCUSSION}

The question of whether or not exergames can be used as a component of an exercise program has intrigued researchers over the past several years. Numerous researchers have concluded that they can be used as a viable alternative to traditional exercise, or at least a component of a traditional exercise program $[15,14,18,22]$. Nonetheless, other researchers have concluded that exergames will not provide a stimulus great enough to contribute to an effective exercise program [6].

In order to ensure the data were valid and reliable, many of the earlier studies examining the EE and HR in young adults were done in a strictly defined fashion, where participants played a specific game at a specific level for a defined length of time. For instance, several previous studies of the Wii Sports Games examined EE of the individual components of the game. Each component played was defined by the researchers ahead of time, including the rest period between components $[6,9,11,20]$. This allowed researchers to accurately determine the level of EE for participants playing that specific part of the game. However, this type of play does not necessarily translate into what happens when the participants play on their own, when they can play any component of the game they desire, and at whatever level they desire. Therefore in each game tested in the current study, the participants were allowed to choose the component of the game they wanted to play, and they could also choose the intensity that they preferred. This method could result in greater generalizability to what would occur if a participant purchased the game and played it on their own. This will not necessarily examine what would occur if an individual were to play this game over a long period of time (weeks or months), but it will at least give an indication what they would expend after learning the game and then playing it on their own.

The ACSM Guidelines [4] consider moderate intensity exercise to be a level that would increase the HR to at least $40 \%$ of HRR, but less than $60 \%$. As can be seen in Table 2, the average HR when combining all games was $125 \pm 20$ bpm. This HR is $44.6 \pm 14.1 \%$ of HRR. Therefore, these exergames contributed to a moderate level of exercise intensity. The only game that did not reach this minimum threshold was the "Just Dance" game.

The ACSM, AHA, and the Surgeon General's Report, all recommend accumulating at least $1,000 \mathrm{kcal}$ per week of physical activity in order to obtain health and fitness benefits [4]. The ACSM guidelines also state this EE is equal to approximately 150 minutes per week or 30 minutes per day of exercise. Therefore, determining how many kcals, on average, need to be expended per minute to reach the recommendations (1000 kcal / 150 minutes of activity), a minimum of $6.7 \mathrm{kcal}$ per minute of activity for 150 minutes per week would be needed as the minimal amount of physical activity. As shown in Table 2, most of the games tested would meet this criterion. Figure 1 shows the level of EE that would be expected if a participant were to play these games or participate in another activity with a similar level of energy expenditure, for 30 minutes a day, for five days per week. Other than the "Just Dance" game, each of the games tested in this study would meet this criterion.
Based on these findings, it seems reasonable to conclude that when an individual plays exergames at a self-selected intensity, similar to those examined in the current study, they are likely to exercise at a level that would be considered moderate exercise. Likewise, if they play these games or similar games regularly enough to spend at least 150 minutes per week, they would reach the recommended guidelines for energy expenditure for the week. It is likely that overtime boredom might set in and therefore individuals would have to play a variety of games or includes other traditional activities in order to maintain these levels of energy expenditure.

Another way of examining the level of EE would be to compare it to a more traditional form of moderate physical activity. When combining all of the participants (pooled data), the average person weighed $70.7 \mathrm{~kg}$. We could therefore use the ACSM metabolic calculations to estimate the level of EE while someone this size was walking [4]. According to these widely accepted formulas, an individual who weighs $70.7 \mathrm{~kg}$ walking on a treadmill at $3.7 \mathrm{mph}$ with a $3 \%$ incline would expend approximately $6.6 \mathrm{kcal} / \mathrm{min}$. This value is similar to the average level of energy expenditure found in the exergames assessed in this study. This comparison provides a clear parallel between a common exercise activity (walking on a treadmill) and a new potential form of exercise (exergaming). It is also important to note, that if utilizing the exergames which required the highest level of EE ("Gold's Gym" and the cardio portion of "Your Shape"), the associated walking speed or incline would be even higher.

\section{CONCLUSION}

The procedures used and the results presented in this study offer a reasonable estimate of the EE that would occur if an individual were to play a particular exergame at his/her chosen level. A similar method could be used to evaluate any of the exergames that are on the market. Based on the ability of these games to meet the ACSM criteria for moderate intensity exercise and weekly EE, it is clear that many exergames could be a solid contributor to an overall exercise program. Fitness professionals could use exergaming as a component of a regular exercise program in order to diversify the exercise program and maintain the interest of the participants.

\section{CONFLICT OF INTEREST}

None declared.

\section{ACKNOWLEDGEMENTS}

This research was supported by a grant from the United States Department of Agriculture (USDA Grant \# 200855215-18837).

\section{REFERENCES}

[1] Haskell WL, Minn LI, Pate RR, et al. Physical activity and public health: updated recommendations from the American College of Sports Medicine and The American heart association. Med Sci Sports Exer 2007; 39:1423-34.

[2] Centers for Disease Control and Prevention. Data 2010: The Healthy People Database. 2011; Available at: http://wonder.cdc. gov/scripts/broker.exe

[3] Rideout VJ, Foehr UG, Roberts DF. Generation $\mathbf{M}^{2}$ : media in the lives of 8- to 18-year-olds. Retrieved from The Henry J. Kaiser 
Family Foundation. 2010; Available at: http://www.kff.org/ entmedia/8010.cfm

[4] American College of Sports Medicine. ACSM's Guidelines for Exercise Testing and Prescription. $8^{\text {th }}$ ed. Lippincott: Williams \& Wilkins 2010.

[5] Lee IM, Skerrett PJ. Physical activity and all-cause mortality: what is the dose-response relation? Med Sci Sports Exerc 2001; 33: S459-71.

[6] Graves LEF, Ridgers ND, Stratton G. The contribution of upper limb and total body movement to adolescents' energy expenditure whilst playing Nintendo Wii. Eur J Appl Physiol 2008; 104: 617-23.

[7] Graves LEF, Ridgers ND, Williams K, Stratton G, Atkinson G, Cable NT. The physiological cost and enjoyment of Wii Fit in adolescents, young adults, and older adults. J Phys Act Health 2010; 7: 393-401.

[8] Miyachi M, Yamamoto K, Ohkawara K, Tanaka S. METS in adults while playing active video games: a metabolic chamber study. Med Sci Sports Exerc 2010; 42: 1149-53.

[9] Graf DL, Pratt LV, Hester CN, Short KR. Playing active video games increases energy expenditure in children. Pediatrics 2009; 124: 534-40.

[10] Haddock BL, Brandt AM, Siegel SR, Wilkin LD, Han JK. Active video games and energy expenditure among the overweight children. Int J Fit 2008; 4: 17-24.

[11] Lanningham-Foster L, Foster RC, McCrady SK, Jensen TB, Mitre $\mathrm{N}$, Levine JA. Activity-promoting games and increased energy expenditure. J Pediatr 2009; 154: 819-23.

[12] Maddison R, Mhurchu CN, Jull A, Yannan J, Prapavessis H, Rodgers A. Energy expended playing video console games: an opportunity to increase children's physical activity? Pediatr Exerc Sci 2007; 19: 334-43.
[13] Mellecker RR, McManus AM. Energy expenditure and cardiovascular responses to seated and active gaming in children. Arch Pediatr Adolesc Med 2008; 162: 886-91.

[14] Unnithan VB, Houser W, Fernhall B. Evaluation of the energy cost of playing a dance simulation video game in overweight and nonoverweight children and adolescents. Int J Sports Med 2006; 27: 804-9.

[15] Barkley JE, Penko A. Physiologic responses, perceived exertion, and hedonics of playing a physical interactive video game relative to a sedentary alternative and treadmill walking in adults. J Exerc Physiol Online 2009; 12: 12-22.

[16] Leatherdale ST, Woodruff SJ, Manske SR. Fatness, energy expenditure while playing active and inactive video games. Am J Health Behav 2010; 34: 31-5.

[17] Siegel SR, Haddock BL, Dubois AM, Wilkin LD. Active video/ arcade games (Exergaming) and energy expenditure in college students. Int J Exerc Sci 2009; 2: 165-74.

[18] Tan B, Aziz AR, Chua K, Teh KC. Aerobic demands of the dance simulation game. Int J Sports Med 2002; 23: 125-9.

[19] Warburton DER, Sarkany D, Johnson M, et al., Metabolic requirements of interactive video game cycling. Med Sci Sports Exerc 2009; 41: 920-6.

[20] Graves L, Stratton G, Ridgers ND, Cable NT. Energy expenditure in adolescents playing new generation computer games. Br J Sports Med 2008; 42: 592-4.

[21] Noble BJ, Borg GA, Jacobs I, Ceci R, Kaiser P. A category-ratio perceived exertion scale: relationship to blood and muscle lactates and heart rate. Med Sci Sports Exerc 1983. 15:523-8.

[22] Kraft JA, Russell WD, Bowman TA, Selsor CW, Foster GD. Heart rate and perceived exertion during self-selected intensities for exergaming compared to traditional exercise in college-age participants. J Strength Cond Res 2011; 25:1736-42.

(C) Haddock et al:; Licensee Bentham Open.

This is an open access article licensed under the terms of the Creative Commons Attribution Non-Commercial License (http://creativecommons.org/licenses/ by-nc/3.0/) which permits unrestricted, non-commercial use, distribution and reproduction in any medium, provided the work is properly cited. 